\title{
Which Thyroid Nodules should be Treated with Surgery?
}

\author{
José L Novelli ${ }^{1}$, Stella M Batallés ${ }^{2}$, Oscar M Brunás ${ }^{3}$, Melisa E Brunás ${ }^{4}$, Anabela V Brunás ${ }^{5}$
}

\begin{abstract}
Aim: The objective of this work was to review the different conditions and characteristics of thyroid nodules that suggest surgical treatment. Background: A systematic literature searching was carried out in main databases (Medline, PubMed, EMBASE, LILACS, Google Academic, SciELO, and The Cochrane Library). The search was restricted to scientific papers published after 2005; only previous works that were inexcusable, specific references were included. The quality and consistency of the recommendations of treatment of thyroid nodules were systematically reviewed and assessed with the AGREE and AGREE-II guidelines. The different conditions and characteristics of thyroid nodules that suggest surgical treatment must be defined by valid, reliable, independent, and easily applied clinical-therapeutic guidelines. Several prestigious organizations from America, Europe, and Asia have developed guidelines containing recommendations for the surgical management of thyroid nodules. However, these recommendations may differ, and that could lead to confusion in many cases. Homogeneous guidelines are required to decide in which cases a thyroid nodule should be treated with a surgical intervention.

Review results: Currently, fine needle aspiration under ultrasound guidance (FNA) has allowed cytological evaluation of non-palpable thyroid nodules from $2 \mathrm{~mm}$ in diameter. Nowadays, both ultrasound and FNA define-in most cases-whether or not a nodule requires surgery.

Conclusion: Not all thyroid nodules require surgery. Surgical treatment is indicated in nodules with confirmed diagnosis or suspected malignancy, when the cytology of an FNA is undetermined, when goiter produces compressive symptoms, in cases of cervicothoracic goiters, recurrent cysts, or when the nodule grows during the follow-up.

Clinical significance: To identify clinical and cytological characteristics in thyroid nodules to decide in which cases a thyroid nodule should be treated with surgery.

Keywords: Neck scar, Nodular goiter, Review article, Surgical approach, Thyroidectomy, Thyroid nodule, Thyroid surgery, Thyroid ultrasound. World Journal of Endocrine Surgery (2021): 10.5005/jp-journals-10002-1406
\end{abstract}

\section{BACKGROUND}

The thyroid nodule is clinically defined as a well-defined macroscopic neoformation, located in the thyroid gland, which must be studied using a protocol involving endocrinologists, biochemists, imaging specialists, pathologists, and surgeons.

Progress in the diagnosis and treatment of thyroid pathology has been remarkable in the last 70 years. During the 1950s, the mere presence of a thyroid nodule was an indication for surgical treatment. Due to the diagnosis was made on the basis of medical signs and palpation method, most cases were large nodular goiters.

Currently, high-resolution ultrasound allows us to identify non-palpable nodules from $2 \mathrm{~mm}$ in diameter. This promotes an increase in prevalence of thyroid nodules, changing both diagnostic and treatment paradigms. In addition, fine needle aspiration under ultrasound guidance (FNA) has allowed cytological evaluation of non-palpable nodules. Nowadays, both ultrasound and FNA define-in most cases-whether or not a nodule requires surgery.

The objective of this work was to review the different conditions and characteristics of thyroid nodules that suggest surgical treatment. These features must be defined by valid, reliable, independent, and easily applied clinical-therapeutic guidelines. ${ }^{1,2}$ Several prestigious organizations from America, Europe, and Asia have developed guidelines containing recommendations for the surgical management of thyroid nodules. However, these recommendations may differ, and that could leads to confusion in many cases. ${ }^{3}$ Clear guidelines are required to decide in which cases a thyroid nodule should be treated with a surgical intervention.

Bibliographic Search: A systematic literature searching was carried out in main databases (Medline, PubMed, EMBASE,

\footnotetext{
${ }^{1-5}$ Thyroid Division, Grupo Oroño, Rosario, Santa Fe, Argentina
}

Corresponding Author: José L Novelli, Thyroid Division, Grupo Oroño, Rosario, Santa Fe, Argentina, Phone: +54 9341 5848684, e-mail: tiroides.novelli@gmail.com

How to cite this article: Novelli JL, Batallés SM, Brunás OM, et al. Which Thyroid Nodules should be Treated with Surgery? World J Endoc Surg 2021;13(2):53-56.

Source of support: $\mathrm{Nil}$

Conflict of interest: None

LILACS, Google Academic, and SciELO). The Cochrane Library was also searched for information on clinical trials in thyroid nodule surgery.

The search was restricted to scientific papers published after 2005; only previous works that were inexcusable specific references were included.

Keywords: As a free search, the key words in Spanish used were: nódulo tiroideo, cirugía tiroidea, ecografía tiroidea, bocio nodular, abordaje quirúrgico, cicatriz post-tiroidectomía. Those used in English were: thyroid nodule, thyroid surgery, thyroid ultrasound, nodular goiter, thyroidectomy, surgical approach, post-thyroidectomy scar.

Logic or "Boolean" operators with key words were used, in Spanish ("$Y$," "O") and in English ("AND," "OR"); the term Mesh: ("Thyroid Neoplasms" [Mesh]) was used for the searching, too.

Theoretical Framework: Initially, the articles were selected according to title, abstract/summary and subsequently, the full texts were accessed. To assess the quality of publications, the AGREE guidelines (Appraisal of Guidelines, Research, and 
Evaluation (AGREE y AGREE-II) 4,5 were applied. Using that tool, we systematically reviewed and assessed the quality and consistency of the recommendations of guidelines on the treatment of thyroid nodules.

With the obtained material and information, the theoretical framework of this paper was written.

\section{Review Results}

Which thyroid nodules should be treated with surgery? Patients with thyroid nodules that present the following characteristics should be considered for surgical treatment:

Nodules with a Confirmed or Suspected Diagnosis of Malignancy: Any nodule with a FNA with Bethesda system IV (follicular neoplasm or suspected follicular neoplasia), V (suspected malignancy), or VI (malignant) must be treated surgically (2015 ATA Recommendation). ${ }^{6}$

Indeterminate Cytology: Between 2 and 18\% of FNA in thyroid nodules are categorized as Bethesda III, with an estimated risk of malignancy between 5 and 15\%. Approximately $6-48 \%$ of thyroid nodes with Bethesda III surgically treated were cancer. ${ }^{7}$ An experience in Rosario (Argentina) showed that $27.7 \%$ of Bethesda III were cancer ( $89 \%$ women). ${ }^{8}$ However, this category per se does not determine surgical treatment and the decision must be taken on a case-by-case basis.

In any FNA classified as Bethesda III category, it is necessary to distinguish whether it is an "atypia of undetermined significance" (AUS) or a "follicular lesion of undetermined significance" (FLUS) ${ }^{9}$ as this could guide the therapeutic behavior.

At 2017 Latin-American Thyroid Congress, Laudi et al. presented the risk of malignancy of Bethesda III, showing that AUS group had significant more risk of being cancer than FLUS group (33.3\% vs $0 \%$; $p<0.01)$. At the same Congress,. Eleonora Hovath et al. showed 269 FNA of thyroid nodules classified as Bethesda III (7.2\% of their casuistic including 3738 thyroid nodes) where 47 were AUS and 222 FLUS. $^{10}$

At our Thyroid Unit in Rosario (Argentina) we identified 117 nodules with FNA that were surgically treated. Bethesda III category represented $22.1 \%$ of FNA ( 26 nodules): five of them (19.2\%) were diagnosed histologically as cancer. We consider it appropriate that thyroid pathology laboratories should indicate both the percentage of indeterminate cytology they record in FNAs and the percentage of them that was diagnosed as malignant after surgery. This could be a laboratory quality indicator.

Nodules with Compressive Symptoms: Compressive symptoms are explained by the anatomical location of the thyroid. Being a gland that is in the anterior part of the neck, when a nodule in its parenchyma begins to grow, it can eventually generate a space-occupying mass, displacing neighboring structures. In these cases, the patient may experience difficulty in swallowing (due to contact with the esophagus), episodes of irritative cough, loss of voice intensity or a feeling of hoarseness (due to contact with the laryngeal nerves) and even a sensation of tightness, and difficulty of the passage of air when performing any physical activity of moderate intensity (by compression of the trachea). In those situations, surgical treatment is indicated. ${ }^{11}$

Cervicothoracic Goiter: It is defined as a goiter in which cervical growth extends caudally toward the chest, favored by gravity, intrathoracic negative pressure, and the space offered by the mediastinum. The aortic arch and subclavian vessels offer an obstacle, greater on the left side, therefore their growth is more frequent to the right. ${ }^{12}$
They appear more frequently in the anterior mediastinum. Functionally, most of the patients are euthyroid. ${ }^{13}$

To study this kind of goiters, the computed tomography is the imaging tool of choice, because this study provide dimensions, extension, and relationship with neighboring structures of the goiter. Histopathologically, they majority are compatible with benign lesions. ${ }^{14,15}$

In asymptomatic patients, indication of surgery is based on the suspicion of malignancy, on the risk of intratumoral hemorrhage that could became a surgical emergency and on the fact that compression of airway could lead to tracheomalacia. ${ }^{16}$

The gold standard management is a total thyroidectomy. Partial resection of thyroid decrease the surgical risk but increase the recurrence rate. Most tumors can be resected by cervicotomy. In big cervicothoracic lesions, a mixed approach (cervical and thoracic) is recommended. The indications of sternotomy appear therefore exceptional, for pure thoracic lesions; these indications are mostly justified for controlling the vessels of endothoracic goiters which present themselves as a voluminous mediastinal tumor with its own mediastinal vascular pedicles. ${ }^{17}$ Thoracotomy is indicated when the goiter is situated in posterior mediastinum. ${ }^{18}$

Recurrent Cysts: The cystic nature of thyroid nodules has historically been considered a good prognostic factor. The proportion of cystic thyroid nodules ranges from $15-37 \% .{ }^{19}$ They may be simple cysts or a cystic degeneration of a preexisting lesion, such as colloid nodules, adenomas, or, more worryingly, papillary carcinomas. Cystic degeneration occurs in $2-4 \%$ of thyroid cancers. ${ }^{20}$

Several studies have shown that the incidence of malignancy in cystic nodules ranges between 7.7 and 29\%. Mixed nodules are malignant more often than pure cysts. This potential malignancy risk had led some authors to try to determine risk factors for selecting patients with a surgical indication. ${ }^{21}$ Abbas et al. detected $12 \%$ of papillary carcinomas in cysts, $12 \%$ of them were incidental microcarcinomas. ${ }^{22}$

The risk of malignancy appears to be greater in large cysts (> 30-35 mm) with hemorrhagic content, when resection is incomplete, when there is recurrence after aspiration, or in patients with a history of radiation in the neck area. ${ }^{23,24}$

Aesthetic Problems of the Scar:The traditional open thyroidectomy, typically performed through a transverse incision made in the anterior lower neck, has been carried out for more than a century. It is safe and its complication rate is low, but in some patients it can cause visible aesthetic problems, mainly due to a vicious scar (e.g., keloid). For this reason, current technological advances in thyroid surgeries are focused on avoiding scars in the neck, studying both minimally invasive and extracervical remote access surgical techniques.

Minimally invasive techniques have attracted interest since the 1980s because these procedures enable the level of "physical invasiveness" and the size of the skin incision to be reduced. ${ }^{25}$ Extracervical remote access techniques have shown considerable evolution with approaches that have included transaxillary, ${ }^{26}$ breast, $^{27}$ postauricular, ${ }^{28}$ and transoral routes ${ }^{29}$ (thyroidectomy with "hidden scar").

The thyroidectomy with transoral route is a new technique (2015) with promising results. Commonly called TOETVA (TransOral Endoscopic Thyroidectomy Vestibular Approach), in this kind of surgery the access to thyroid is thorough the mouth vestibule with an endoscopy. ${ }^{30}$ Parathyroidectomies are undergoing with the same approach, too. ${ }^{31}$ 
It should be noted that the use of all these approaches requires intensive training with the instrumental manipulation as well as surgeons with experience in endocrine and endoscopic surgery. They are approaches for selected patients and have an aesthetic purpose. They are not part of standard conventional surgery.

When a Nodule Grows During Follow-up: Some thyroid nodules, after being evaluated, have no surgical indication and they are treated with thyroid hormone and controls awaiting their reduction.

When the nodule grows in size during follow-up, it is suggested to reevaluate them with ultrasound and FNA; surgery could be the treatment.

\section{Discussion}

Nowadays, both ultrasound and FNA define-in most caseswhether or not a nodule requires surgery. Multiple guidelines proposed by worldwide scientific organizations differ among them in the surgical management of thyroid nodules, and those lead to confusion in many cases. Homogeneous rules are required to decide in which cases a thyroid nodule should be treated with a surgery intervention.

\section{Conclusion}

Not all thyroid nodules require surgery. Surgical treatment is indicated in:

- Nodules with confirmed diagnosis or suspected malignancy.

- Nodules with undetermined cytology (decision made on a case by case basis).

- Nodules with compressive symptoms.

- Cervicothoracic goiters.

- Recurrent cysts.

- Growth of the nodule during the follow-up.

\section{Clinical Significance}

To identify clinical and cytological characteristics to decide in which cases a thyroid nodule should be treated with a surgical intervention.

\section{Acknowledgments}

The authors thank to surgeons Vanesa Verdun, Mariano Maggioni and Fernando Poentiz.

\section{References}

1. Grilli R, Magrini N, Penna A, et al. Practice guidelines developed by specialty societies: the need for a critical appraisal Lancet 2000;355((9198)):103-106. DOI: 10.1016/S0140-6736(99)02171-6

2. Graham ID, Harrison MB. Evaluation and adaptation of clinical practice guidelines. Evid Based Nurs 2005;8:68-72. DOI:10.1136/ebn.8.3.68

3. Oxman AD, Glasziou P, Williams JW. What should clinicians do when faced with conflicting recommendations? BMJ 2008;337:a2530. DOI: $10.1136 /$ bmj.a2530

4. The AGREE Research Trust. Appraisal of Guidelines for Research and Evaluation II Instrument. Edited by: Brouwers MC. 2009. Available from: http://www.agreetrust.org (Consulted 03/22/2010)

5. Brouwers MC, Kho ME, Browman GP, et al. AGREE II: Advancing guideline development, reporting and evaluation in healthcare. CMAJ 2010;182(18):839-842. DOI: 10.1503/cmaj.090449

6. Haugen BR, Alexander EK, Bible KC, et al. 2015 American Thyroid Association Management guidelines for adult patients with thyroid nodules and differentiated thyroid cancer: The American
Thyroid Association guidelines task force on thyroid nodules and differentiated thyroid cancer. Thyroid 2016;26(1):1-133. DOI: 10.1089/thy.2015.0020

7. Ali SZ, Cibas ES. The Bethesda System for reporting thyroid cytopathology (2nd ed). Boston: Springer; 2018. DOI: 10.1089/thy.2009.0274

8. Demaria L, Maggioni M, et al. Clasificación Anatomopatológica Bethesda III: Nuestra experiencia en los últimos 18 meses. XXV Argentine Congress of Head and Neck Surgeons Argentine Association. Rosario (Argentina) Sept 30th - Oct 2nd, 2015.

9. Sabino de Matos P. Anatomía patológica y citología. En: JL Novelli y LS Ward (eds) Bocio nodular benigno. Rosario: UNR Editora; 2013:151-159.

10. XVI Latin American Thyroid Congress. Rio de Janeiro (BR) June 15-18th, 2017.

11. Eng OS, Potdevin L, Davidov T, et al. Does nodule size predict compressive symptoms in patients with thyroid nodules? Gland Surg 2014;3(4):232-236. DOI: 10.3978/j.issn.2227-684X.2014.08.03

12. Rabiou S, Ammor FZ, Aminou SM, et al. Difficulties in the choice of surgical approach in cervicothoracic goiters Clin Surg 2017;2(1):1419. Available from: https://www.researchgate.net/ publication/316762668_Difficulties_in_the_Choice_of_Surgical_ Approach_in_Cervicothoracic_Goiters

13. González L, Cifuentes C, Jadue A, et al. Caracterización y resultados inmediatos en pacientes con tratamiento quirúrgico de bocio intratorácico. Rev Chil Cir 2012;64:426-433. Available from: https:// scielo.conicyt.cl/scielo.php?script=sci_abstract $\&$ pid $=$ S0718 40262012000500003\&lng=pt\&nrm=iso (Consulted 03/20/2020)

14. Agarwal G, Aggarwal V. Is total thyroidectomy the surgical procedure of choice for benign multinodular goiter? An evidence-based review. World J Surg 2008;32(7):1313-1324. DOI: 10.1007/s00268-008-9579-8

15. Tezelman S, Borucu I, Giles YS, et al. The change in surgical practice from subtotal to near-total or total thyroidectomy in the treatment of patients with benign multinodular goiter World J Surg 2009;33(3):400-405. DOI:10.1007/s00268-008-9808-1

16. De Aquiar-Quevedo K, Cerón-Navarro J, Jordá-Aragón C, et al. Intrathoracic goitre: a literature review Cir Esp 2010;88(3):142-145. DOI: 10.1016/j.ciresp.2010.03.020

17. Lifante JC, Fernandez Vila JM, Mingoutaud L, et al. Indications for sternotomy in thyroid surgery. Evolution over 20 years' experience. J Chir (Paris) 2007;144(3):221-224. DOI: 10.1016/s0021-7697(07)89519-6

18. Lavanderos J, Cacciuttolo G, Cheyre JE. Bocio gigante cérvico-torácico. Revista chilena de cirugía 2014;66(5):414-415. Available from: https:// scielo.conicyt.cl/pdf/rchcir/v66n5/art02.pdf (Consulted 03/22/2020). DOI: $10.4067 /$ S0718-40262014000500002

19. Mazzaferri EL. Management of solitary thyroid nodule. N Engl Med 1993;328:553-559. DOI: 10.1056/NEJM199302253280807

20. Miller JM, Uz Zafar S, Karo JJ. The cystic thyroid nodule. Radiology 1974;110(2):257-261. DOI: 10.1148/110.2.257

21. Pla-Martí V, Fernández-Martínez C, Pallas-Regueira A, et al. Actitud ante los quistes tiroideos recidivantes con citología benigna. Cir Esp 2005;77(5):267-270. DOI: 10.1016/S0009-739X(05)70852-6

22. Abbas G, Heller KS, Khoynezhad A, et al. The incidence of carcinoma in cytologically benign thyroid cysts. Surgery 2001;130(6):1035-1038. DOI: 10.1067/msy.2001.118387

23. Meko JB, Norton JA. Large cystic/solid thyroid nodules: a potential false-negative fine-needle aspiration. Surgery 1995;118(6):996-1003. DOI: 10.1016/s0039-6060(05)80105-9

24. Hammer M, Worstman J, Folse R. Cancer in cystic lesions of the thyroid. Arch Surg 1982;117(8):1020-1023. DOI: 10.1001/archsurg.1982.01380320016005

25. Campbell MJ, Duh Q-Y. Defining minimally invasive and remote access surgery of the thyroid and parathyroid glands. In: Minimally Invasive and Robotic Thyroid and Parathyroid Surgery; Terris D, Singer M Ed. New York(NY, USA): Springer; 2014:7-16. DOI: 10.1007/978-1-4614-9011-1_2

26. Ikeda $Y$, Takami H, Sasaki Y. Endoscopic neck surgery by the axillary approach. J Am Coll Surg 2000;191(3):336-340. DOI:10.1016/S10727515(00)00342-2 
27. Choe J-H, Kim SW, Chung K-W, et al. Endoscopic thyroidectomy using a new bilateral axillo-breast approach. World J Surg 2007;31(3): 601-606. DOI:10.1007/s00268-006-0481-y

28. Lee KE, Kim HY, Park WS, et al. Postauricular and axillary approach endoscopic neck surgery: a new technique. World J Surg 2009;33(4):767-772. DOI: 10.1007/s00268-009-9922-8

29. Witzel K, Von Rahden BHA, Kaminski C et al. Transoral access for endoscopic thyroid resection. Surg Endosc 2008;22(8):1871-1875. DOI: 10.1007/s00464-007-9734-6
30. Anuwong A, Ketwong K, Jitpratoom P, et al. Safety and outcomes of the transoral endoscopic thyroidectomy vestibular approach. JAMA Surg 2018;153(1):21-27. DOI: 10.1001/jamasurg.2017.3366

31. Khafif AH, Alon E, Assadi N. Scarless thyroidectomy and parathyroidectomy by transoral endoscopic transvestibular approach (TOETVA): the first series cases in Israel Harefuah 2019;158(11):716-720. Hebrew. PMID: 31721513. 